\title{
Flexural Performance of Concrete Beam Strengthened with Multi-supports Unbounded Prestressed CFRP Plate
}

\author{
Jinyu $\mathrm{Li}^{1,}$, , Xinsheng $\mathrm{Xu}^{1, \mathrm{~b}}$ \\ ${ }^{1}$ University of Jinan, Jinan, Shan dong, China \\ ayxshlijinyu@163.com, b13665316591@163.com
}

\begin{abstract}
Keywords: Muiti-supports,Unbonded,ABAQUS,Concrete Beam Reinforced with CFRP
Abstract. The multi-supports unbonded prestressed CFRP plate reinforcement technology is introduced and ABAQUS finite element software is used to establish a multi-supports unbounded prestressed CFRP plate reinforced concrete beam model.The bending stiffness,bearing capacity and deformation regulation of finite element model is analyzed and compared by changing the number and spacing of the support and degree of prestressing.And the effect of changing these parameters on bearing capacity of concrete beams strengthened with multi-supports unbonded prestressed CFRP plate is also analyzed and compared.
\end{abstract}

\section{Introduction}

Traditional bonded prestressed CFRP sheet reinforcement technology is not only complicatedly in constructing and slow, and affected by the construction quality,anchorage measures,bonding material aging and debonding failure.Which resulted in CFRP strength will not make full use of,affected the effectiveness of strengthening. And the existing unbonded prestressed CFRP sheet reinforcement technology replace the traditional bonded technology for complex process, shortening construction period,and replacement of CFRP sheets is simple and fast.But the CFRP sheet utilization is lower compared with bonded technology.

In order to makes full use of the advantages of high strength of CFRP, 'A multi-supports unbonded prestressed CFRP plate reinforcement' technology is proposed which mainly rely on plate anchor and screw bolt system. The unbonded prestressed CFRP plate connect to strengthened flexural members by the end plate anchor and the independent development plate anchor(that is supports) at the middle part.It allows the unbonded prestressed CFRP plate along the longitudinal direction of the relative sliding while the deformation of the other direction is restricted.The reinforcement effect mainly depends on the force transmission of multi-supports and prestress CFRP,thus high strength of CFRP plate is effectively used.The technology not only makes full use of high strength performance of CFRP plate and improves the structure durability and fire resistance and can effectively prevent debonding failure,thus can greatly increase the seismic performance of concrete structure.The specific structure is shown in Figure. 1 and figure. 2.

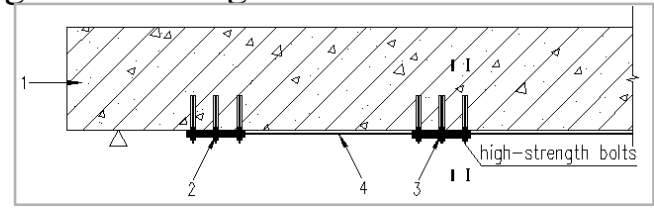

Figure. 1 A Multi-Supports Unbonded Prestressed CFRP Plate Anchorage System

1-Reinforced Concrete Beam; 2-End Plate Anchor;

3-Independent Development Plate Anchor at The Middle Part; 4-CFRP Plate 


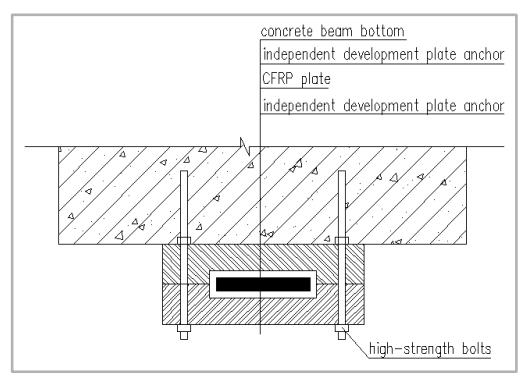

Figure. 2 The Middle Independent Development Plate Anchor Structure Detail(I-I)

\section{Establishment of The Finite Element Model}

The'multi-supports unbonded prestressed CFRP plate reinforced concrete beam'finite element model is established with ABAQUS software and different parameters are simulated and analyzed.The study is based on the test research by Kan Kang et $\mathrm{al}^{[1]}$. Two unbonded prestressed CFRP concrete beams and one reference beam is selected as the prototype.

The separation model ${ }^{[6]}$ is selected as calculation model.Reduction one C3D8R solid element simulate concrete and concrete plastic damage model is used to simulate mechanical performance of concrete in which only definite plastic properties of concrete materials without considering the plastic damage of concrete ${ }^{[3,4]}$.Zhenhai Guo's stress-strain expression simulate the stress-strain relationship of concrete under uniaxial compression and tension condition ${ }^{[5]}$.Steel chose truss T3D2 element and ideal elastic-plastic constitutive model is adopted.The CFRP plate is simplified as the isotropic linear elastic material and its stress-strain relationship selects ideal brittle-elastic model.Temperature-rising method is adopted to prestress the CFRP plate.Rigid springs ${ }^{[2]}$ (that is supports) are arranged between concrete beam element and the CFRP plate to simulate the deformation characteristics of multi-supports unbonded prestressed beam and the springa element is used to simulate rigid springs.Compartmentalizing calculating mesh rationally.Simply supported beams constraints are adopted to exert boundary condition.

\section{Simulation Analysis of Parameter Influence}

Simulation Analysis of The Number And Spacing of Different Supports.The unstrengthened beams C,one support strengthened beams PU-3R(1),two supports strengtrend beams PU-3R(2) and three supports strengthened beams PU-3R (3) are selected as the numerical simulation object.The beams $C$ is used as control beams. The areas of CFRP plate and prestress levels of beams PU-3R(1), PU-3R(2),PU-3R(3) have no difference, in addition to the different number of supports.Prestress degree of PU-3R(1), PU-3R(2),PU-3R(3) is $0.3 f_{\mathrm{u}}$. It's model is shown in Figure. 3.

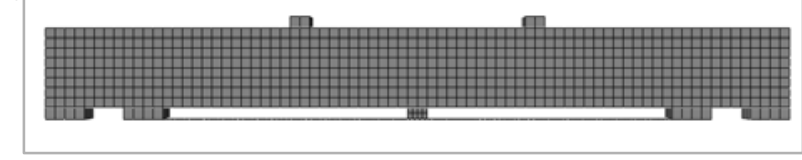

(a) The Model of One Support

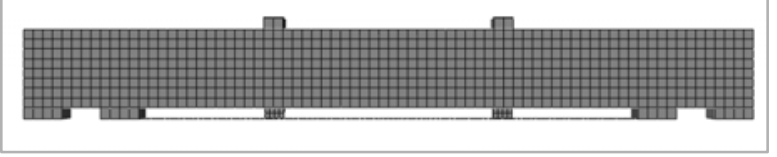

(b) The Model of Two Supports

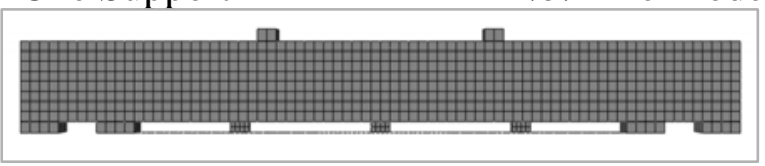

(c) The Model of Three Supports

Figure. 3 Model of Strengthened Beams

Load-Deflection Curve.The simulation results of different supports number,spacing and control beam test results were compared and analyzed.Figure. 4 showes the load-deflection curve.As can be seen that in the case of the same ultimate bearing capacity,the mid-span deflection was reduced by $18.4 \%, 22.1 \%, 27.5 \%$ compared to the control beams with the increase in the number of supports of PU-3R (1) PU-3R (3). 


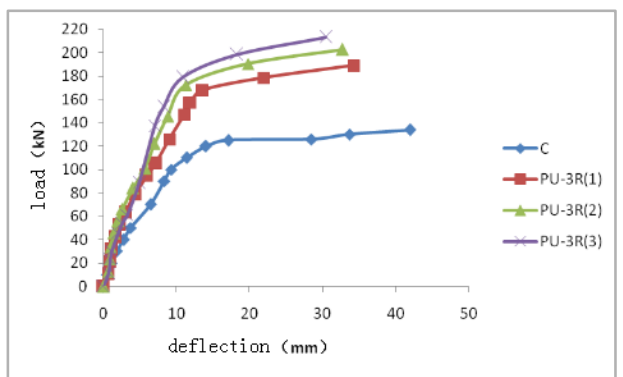

Figure. 4 Comparison Curve of Mid-Span Load-Deflection

Figure. 4 showes the load-deflection curve.We can seen that in the case of the same ultimate bearing capacity,the mid-span deflection was reduced by $18.4 \%, 22.1 \%, 27.5 \%$ compared to the control beams with the increase in the number of supports of PU-3R (1) PU-3R (3).

Analysis of Bearing Performance of Test Beam.The comparison between ABAQUS numerical simulation of the various stages of the load and the test results of control beams $C$ is shown in Table 1.Each stage load of PU-3R(1) PU-3R (3) is almost identical, while has been improved greatly compared to the control beams $\mathrm{C}$,by an average of $43 \%, 47 \%$ and $49 \%$.Therefore, the load value of each stage of the test beam obviously rise with the increase of the prestress levels.And the yield load and ultimate load also increase with the increase of the number of the supports.

Table 1 Analysis of Bearing Performance of Test Beam

\begin{tabular}{cccccccc}
\hline $\begin{array}{c}\text { Test Beam } \\
\text { Number }\end{array}$ & $\begin{array}{c}\text { Supports } \\
\text { Number }\end{array}$ & $\begin{array}{c}\text { Cracking } \\
\text { Load[kN] }\end{array}$ & $\begin{array}{c}\text { Increase } \\
\text { Coefficient }\end{array}$ & $\begin{array}{c}\text { Yielding } \\
\text { Load[kN] }\end{array}$ & $\begin{array}{c}\text { Increase } \\
\text { Coefficient }\end{array}$ & $\begin{array}{c}\text { Ultimate } \\
\text { Load[kN] }\end{array}$ & $\begin{array}{c}\text { Increase } \\
\text { Coefficient }\end{array}$ \\
\hline C & $/$ & 27 & $/$ & 101 & $/$ & 134 & $/$ \\
PU-3R(1) & 1 & 37 & 0.37 & 144 & 0.43 & 189 & 0.41 \\
PU-3R(2) & 2 & 40 & 0.48 & 149 & 0.48 & 203 & 0.51 \\
PU-3R(3) & 3 & 39 & 0.44 & 151 & 0.50 & 206 & 0.54 \\
\hline
\end{tabular}

Comparative Analysis of Different Prestress Levels.Under the circumstances of same areas of CFRP plate,to change prestress degree of CFRP plate,in which PU-2R and PU-3R respectively represented $20 \%$ and $30 \%$ of prestress degree.

Load-Deflection Curve. The different prestress degree of the ABAQUS results and control beam test results is compared and analyzed and plotted a series of test beam load-deflection curves.As shown in Figure. 5.

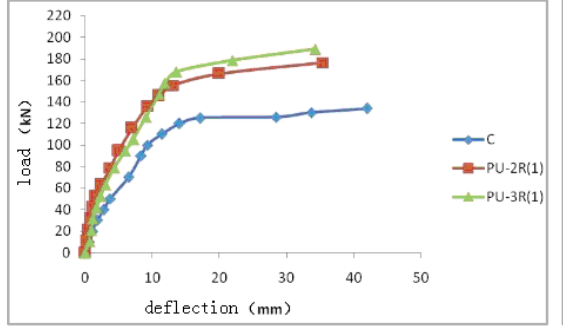

(a) One Support Beams

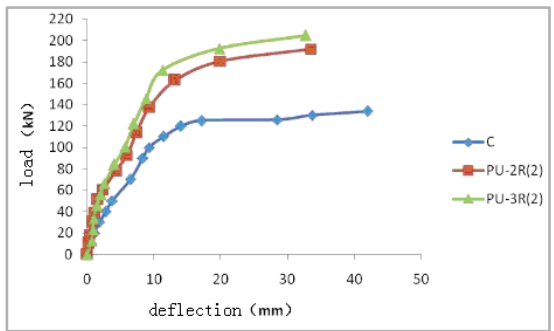

(b) Two Supports Beams

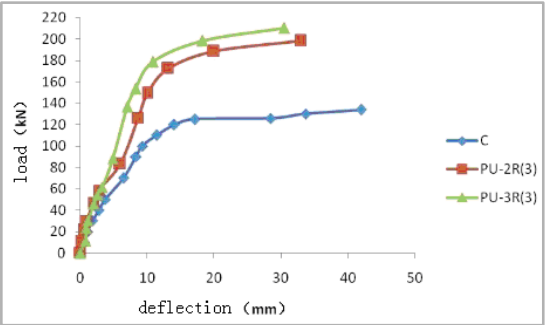

(c) Three Supports Beams

Figure. 5 Comparison of Load-Deflection Curves of Multi-Support Unbonded Prestressed Concrete Beams

Through the comparative analysis of test beam load-deflection curves it can be get: compared with control beams C, the multi-supports unbonded prestressed CFRP plate reinforced concrete beam's load at each stage increased significantly.To a certain extent, with the increase of the prestress levels, the bending deformation of the test beam significantly reduce and bending stiffness increase.

Analysis of Bearing Performance of Test Beam.The comparison between ABAQUS numerical simulation results and the test results of the control beams $C$ are shown in Table 2. We can see that the 
impact of the prestress on the flexural capacity of concrete beams is obvious. In a certain range, the prestress can significantly improve the flexural capacity of concrete beams. The greater the prestress, the various stages of load (including cracking, yielding and ultimate load, etc.) increase obviously.

Table 2 Analysis of Bearing Performance of Test beam

\begin{tabular}{cccccccc}
\hline $\begin{array}{c}\text { Test Beam } \\
\text { Number }\end{array}$ & $\begin{array}{c}\text { Supports } \\
\text { Number }\end{array}$ & $\begin{array}{c}\text { Cracking } \\
\text { Load[kN] }\end{array}$ & $\begin{array}{c}\text { Increase } \\
\text { Coefficient }\end{array}$ & $\begin{array}{c}\text { Yielding } \\
\text { Load[kN] }\end{array}$ & $\begin{array}{c}\text { Increase } \\
\text { Coefficient }\end{array}$ & $\begin{array}{c}\text { Ultimate } \\
\text { Load[kN] }\end{array}$ & $\begin{array}{c}\text { Increase } \\
\text { Coefficient }\end{array}$ \\
\hline C & $/$ & 27 & $/$ & 101 & $/$ & 134 & $/$ \\
PU-2R(1) & 1 & 34 & 0.26 & 139 & 0.38 & 176 & 0.32 \\
PU-3R(1) & 1 & 37 & 0.37 & 144 & 0.43 & 189 & 0.41 \\
PU-2R(2) & 2 & 38 & 0.41 & 143 & 0.42 & 192 & 0.43 \\
PU-3R(2) & 2 & 40 & 0.48 & 149 & 0.48 & 203 & 0.51 \\
PU-2R(3) & 3 & 36 & 0.33 & 147 & 0.46 & 198 & 0.48 \\
PU-3R(3) & 3 & 39 & 0.44 & 151 & 0.50 & 206 & 0.54 \\
\hline
\end{tabular}

\section{Conclusions}

Through analyzing and comparing of bending stiffness, bearing capacity and deformation's regulation of finite element model,we draw the following conclusions:

(1)In a certain range,the greater the degree of prestress applied to CFRP plate,the concrete beams flexural stiffness is larger.The improvement of prestress levels can effectively reduce the concrete beams bending deformation, significantly improve concrete beams bending stiffness and the bearing capacity, also can delay the concrete cracking and suppress the cracking.

(2)Supports number and spacing of reinforced concrete beams with bending stiffness, bearing capacity and deformation have certain effect: mid-span deflection obviously decrease with the increase of the number of supports, while the yield load and ultimate load increase accordingly. But when the supports increased to a certain number, the ultimate load tends to be stable. So, when used in practical engineering, we should fully consider various factors and establish efficient and reasonable reinforcement scheme.Therefore, the reinforcement effect really works.

\section{Acknowledgements}

The work was supported by the natural science foundation of Shandong province of china under Grant No ZR2014EEM036 and the project of science and technology plan of Jinan under Grant No 201305029.

\section{References}

[1]M.A.Kan Kang : Experimental study on flexural behavior of reinforced concrete strengthened with ends anchor unbonded prestressed CFRP plate (Guangxi University of Technology, Guangxi 2012).(In Chinese)

[2] M.A.Tiejiong Lou: Finite element modeling and analytical study on the behavior of unbonded prestressed beams(Zhejiang University,Zhejiang 2005).(In Chinese)

[3]Zhanting Zhang , Yufeng Liu: Building Structure. Journal Vol. 41(2011), p. 129-131.(In Chinese)

[4]Jianguo Nie , Yuhang Wang : Engineering Mechanics.Journal Vol. 30(2013), p. 59-67.(In

Chinese) 
[5] Zhenhai Guo, Xudong Shi. Principle And Analysis of Reinforced Concrete Structure,edtied by Tsinghua University Publishing, Beijing,2003,in press.(In Chinese)

[6]Jianjing Jiang. Nonlinear Finite Element Analysis of Reinforced Concrete Structure, edtied by Shanxi Science and Technology Publishing, Xi'an,1994, in press.(In Chinese) 